\title{
L428 cell morphophenotypic changes induced by CD99 overexpression via NF-kB inactivation
}

\author{
Zuoping Huang, Feng Li, BinXin Zhou, Ying Liu, Xin Qian, Xiao Liu, Xingjing Liu \\ The Affiliated WuJ ing Hospital of Guangzhou Medical College, Guangzhou, China.
}

Correspondence: Zuoping Huang. Address: The Affiliated WuJ ing Hospital of Guangzhou Medical College, State Key Laboratory of Respiratory Disease, Guangzhou, 510507, China. Email: zuoping68@126.com, liuxingjing023@21cn.com

Received: October 21, 2012

Accepted: January 28, 2013

Online Published: February 5, 2013

DOI: $10.5430 / \mathrm{jhm} . v 3 \mathrm{n} 1 \mathrm{p} 7$

URL: http://dx.doi.org/10.5430/jhm.v3n1p7

\begin{abstract}
Background: Classic Hodgkin's lymphoma (HL) is characterized by the presence of Hodgkin and Reed-Sternberg (HRS) cells. CD99 downregulation produces HRS-like cells and morphological changes in B lymphoma. The NF- $\mathrm{kB}$ pathway protects HRS cells from apoptosis and is in part responsible for its unique functional characteristics in Hodgkin's lymphoma.

Objective: To observe the changes in the morphological and immunophenotype characteristics of L428 cells following transformation with CD99 and explore the role of NF- $\mathrm{KB}$ in these changes.

Methods: A mammalian expression vector driving CD99 was constructed and transfected into the L428 cell line (L428-MVC). L428, L428-EVC (empty vector) and L428-MVC were analyzed by immunohistochemistry (IHC), immunofluorescence, and Western blot analysis, and comparisons were made between the three cell lines with regards to the expression of CD2, CD3, CD15, CD20, CD30, CD79, CD99 and NF- $\mathrm{kBp} 65$. In addition, cell proliferation was monitored by MTT assay, while apoptosis and cell cycle status were determined by flow cytometry.

Results: Transfection of L428 cells with CD99 altered the morphological and immunophenotypic characteristics of HRS cells. Expression of CD15, CD30, and NF-אBp65 disappeared, while CD2, CD3, CD20 and CD79 levels remained negative. In addition, the presence of CD99 led to cell cycle arrest at G2/M and a reduction in cell proliferation. More importantly, CD99 dramatically decreased cell viability and increased cellular apoptosis compared with naive L428 cells and the L428-EVC cell line. These results indicated that the upregulation of CD99 altered cell morphology and immunophenotype, while also decreasing viability in vitro.
\end{abstract}

Conclusions: CD99 may play a key role in affecting cell morphology and immunophenotype characteristics via

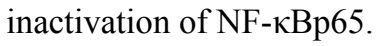

\section{Key words}

Hodgkin's lymphoma, CD99, L428, NF-kB

\section{Introduction}

Hodgkin's lymphoma (HL), the common type of malignant lymphoma in China, is a lymphoid neoplasm characterized by a low frequency of malignant tumor giant cells. It is distinguished from other tumors by the presence of Hodgkin and 
Reed-Sternberg (HRS) cells ${ }^{[1]}$. The nature and origin of HRS cells are still unclear despite much investigation at the molecular level. In recent years several mechanisms for the development of HL have been considered, including latent infection with Epstein-Barr virus (EBV), nuclear NF-kB, Notch-1 signaling, resistance to death-receptor-mediated apoptosis, and a proliferation defect caused by abortive mitotic cycles that allows HL cells to survive and develop ${ }^{[2-5]}$. Interestingly, LMP1-mediated NF- $\mathrm{KB}$ signaling plays a major role in repressing transcription at the CD99 promoter ${ }^{[6]}$. Analysis of the properties of HRS cells, including the presence of genetic abnormalities, single cell analysis of gene rearrangements, aberrant activation of NF- $\mathrm{kB}$ and resistance to apoptosis, have indicated that NF- $\mathrm{KB}$ and CD99 have a close relationship with regards to the origin of HRS cells ${ }^{[7]}$.

It is imperative to elucidate the pathogenesis of $\mathrm{HL}$ and, in particular, the molecular events leading to transformation into HRS cells. Kim et al. have shown that downregulation of CD99 leads to the production of HRS-like cells in B lymphoma ${ }^{[8]}$. CD99, a $32 \mathrm{kDa}$ protein, can cause pronounced tyrosine phosphorylation in signal transduction pathways and has been linked to various tumors. Various types of cells, including monocytes, neutrophils and hematopoietic progenitor cells, express CD99 ${ }^{[9,10]}$, and CD99 is typically regarded as the most useful single marker in the diagnosis of synovial sarcoma, malignant peripheral nerve sheath tumor, and Ewing's sarcoma ${ }^{[11]}$. One report suggested that CD99 is expressed in non-Hodgkin's lymphoma ${ }^{[12]}$. Nevertheless, the changes that occur following transfection of CD99 into a HL cell line have not yet been elucidated.

CD99 downregulation produced HRS-like cells and morphological changes in B lymphoma. NF- $\mathrm{kB}$ activation protects HRS cells and is responsible for their functional characteristics in Hodgkin's lymphoma. In this study, we investigated the changes taking place in the HL cell line L428 following upregulation of CD99 and explored the relationship between the morphology and functional changes.

\section{Methods}

\subsection{Tissue and cell}

Lymph node tissue was obtained from 15 patients with HL. The histological subtypes were distributed as follows: nodular lymphocyte-predominant HL (2/15), nodular sclerosis HL (6/15), and mixed cellularity HL (7/15). The HL cell line L428 was kindly donated by professor Chan of the Nebraska Medical Center in the U.S.A. This cell line was established from the pleural effusion of a 37-year-old woman with HL (stage IVB, nodular sclerosis, and refractory, terminal) in 1978. Optical and fluorescence microscopy was performed using Olympus BX61 Motorized System and Motorized reflected Fluorescence System microscopes (Olympus Company; Japan). Flow cytometry was performed with a device manufactured by Beckman Coulter (USA). The L428 cells were grown in RPMI 1640 media supplemented with $20 \%$ heat-inactivated fetal calf serum (FCS). The study was approved by the Ethics Committee of Southern Hospital and all participants signed an informed consent form.

\subsection{RNA isolation and RT-PCR}

Total RNA was isolated from a Jurkat line (maintained by our department) using Trizol reagent (Sigma; USA). Two PCR products encompassing CD99 and glyceraldehyde phosphate dehydrogenase (GAPDH) and spanning 585 bp were amplified by forward primer 5'-ATT GGT ACC ATG GCC CGC GGG GCT GC -3' and reverse primer 5'-ATC GGG CCC CTA TTT CTC TAA AAG AGT ACG -3'. With GAPDH as an internal control, the forward primer 5'-CCT TCT GCC GAT GCC CCC AT-3' and reverse primer 5'-CAT TGT CAT ACC AGG AAA TG-3'. PCR was performed in a final volume of $25 \mu \mathrm{L}$ containing $10 \mathrm{pmol}$ of each primer, $10 \mathrm{mM}$ Tris- $\mathrm{Cl}$ ( $\mathrm{pH} 8.5$ ), $50 \mathrm{mM} \mathrm{KCl}, 1.5 \mathrm{mM} \mathrm{MgCl} 2,200 \mu \mathrm{M}$ of each dNTP, 1.5 units of Taq polymerase (Promega, USA) and $1000 \mathrm{ng}$ of genomic RNA. After incubation for 5 min at $95^{\circ} \mathrm{C}, 35$ cycles of $50 \mathrm{~s}$ at $95^{\circ} \mathrm{C}, 40 \mathrm{~s}$ at $65^{\circ} \mathrm{C}$, and $40 \mathrm{~s}$ at $72^{\circ} \mathrm{C}$ were performed, followed by $10 \mathrm{~min}$ at $72^{\circ} \mathrm{C}$. The amplified fragments were detected by $1 \%$ agarose gel electrophoresis. 


\subsection{CD99 cloning and transfection and siRNA against CD99}

PCR products were separated on a $2 \%$ agarose gel containing $0.3 \mathrm{mg} / \mathrm{mL}$ ethidium bromide and purified using the QIAquick purification system (Qiagen; Germany) according to the manufacturer's protocol. A full-length CD99 cDNA was inserted into the Apa I and Kpn I sites of the mammalian expression vector pcDNA3.1 (+). This plasmid, as well as an empty expression vector (termed L428-EVC, a negative control), was introduced into cells by electroporation. Establishment and subcloning of stable cell lines was accomplished by culturing primary transfectants in the presence of $500 \mu \mathrm{g} / \mathrm{mL}$ G-418 (GIBCO-BRL) for 1 month. The stable cell line expressing CD99 was named L428-MVC.The CD99 siRNA sequences were 5'-CAC CGG GAT GGT GGT TTC GAT TTA CGA ATA AAT CGA AAC CAC CAT CCG GAC AAG G-3' (top strand) and the 5'-AAA AGG ATG GTG GTT TCG ATT TAT TCG TAA ATC GAA ACC ACC ATC CC-3' (bottom strand). The siRNA for CD99 was inserted into the pGEM®-T Easy vector, which was then transfected into L428-MCV cells using the BLOCK-iT ${ }^{\mathrm{TM}}$ Lentiviral RNAi Expression System (Invitrogen; USA).

\subsection{DNA sequencing}

Genomic DNA was extracted from one of the L428-MVC clones, which was subjected to lysis (in $0.5-1.0 \mathrm{~mL}$ cell lysis buffer containing $100 \mathrm{mmol} / \mathrm{L}$ Tris- $\mathrm{Cl} \mathrm{pH} 8.5,20 \mathrm{mmol} / \mathrm{L}$ EDTA, $20 \mathrm{mmol} / \mathrm{L} \mathrm{NaCl}, 2.0 \% \mathrm{SDS}$, and 0.5-2.0 mg/mL proteinase K) followed by conventional phenol/chloroform extraction. DNA fragments were sequenced from the plasmid T7 promoter with the ABI Prism Dye Terminator Cycle Sequencing System (Perkin-Elmer; Foster City, CA). The sequences were aligned with the CD99 germline sequence (GenBank accession number AF191831) with use of BLAST online software (www.ncbi.nih.gov/blast).

\subsection{Immunohistochemical and morphological examination of cell lines}

Immunohistochemical stainings were performed on L428, L428-EVC, and L428-MVC cells. Rabbit anti-p65 -immunoglobulin G (IgG) and fluorescein isothiocyanate (FITC)-labeled mouse anti-rabbit IgG (Invitrogen, CA; USA) were stained according to the manufacturer's instructions. The L428 and L428-MVC cells were combined with anti-CD20, anti-CD30, anti-CD15, anti-CD2, anti-CD3, anti-CD79, anti-NF-kBp65 and anti-CD99 antibodies (Invitrogen, $\mathrm{CA}$; USA), followed by standard $\mathrm{ABC}$ staining and development with diaminobenzidine tetrahydrochloride (DAB) substrate. NF- $\kappa$ B activation was blocked with bortezomib (Velcade, Millennium Pharmaceuticals; USA). The morphology of the L428, L428-EVC, and L428-MVC cells was assessed with a fluorescence microscope (Olympus BX61 Motorized Microscope, Japan) and by flow cytometric analysis.

\subsection{Western blotting}

Samples were electrophoresed on sodium dodecyl sulfate (SDS) polyacrylamide gels and transferred to a polyvinylidene difluoride (PVDF) membrane. The membranes were blocked for $1 \mathrm{~h}$ in Tris-buffered saline at $\mathrm{pH} 7.2$ with $0.1 \%$ Tween (TBST) containing 3\% BSA. Primary antibodies were added to the blocking buffer and the membranes were incubated overnight at $4{ }^{\circ} \mathrm{C}$. The membranes were incubated with horseradish peroxidase-conjugated secondary antibodies in TBST with $5 \%$ nonfat dry milk for $1 \mathrm{~h}$ at room temperature. The proteins were visualized by chemiluminescence on Kodak BioMax MR Films.

\subsection{Flow cytometric analysis}

For staining, 106 cells were first incubated with the relevant monoclonal antibodies $(1 \mu \mathrm{g} / 100 \mu \mathrm{L})$ in phosphate-buffered saline (PBS) containing $1 \%$ bovine serum albumin (BSA) and $0.1 \%$ sodium azide for $30 \mathrm{~min}$ at $4^{\circ} \mathrm{C}$. The cells were stained with fluorescein isothiocyanate (FITC)-conjugated goat anti-mouse IgG antibodies and analyzed on a FACScan flow cytometer (Becton Dickinson; San Jose, CA). The cells were stained with propidium iodide as described by the manufacturer's instructions (BD PharMingen; San Diego, CA) to detect apoptosis. The following reagents were also employed during flow cytometry analysis: IgG1-FITC/IgG1-PE (Immunotech; Marseille, France), CD30-FITC, CD15-FITC and CD20-FITC (BD Biosciences; San Jose, CA USA). 


\subsection{Cell proliferation assays}

To quantify cell viability, live cells were counted using light microscopy after trypan blue staining. To quantify cell proliferation, we used the MTT tetrazolium dye reduction assay. Cells were seeded in triplicate into the wells of a 96-well flat-bottom tissue culture plate at $2 \times 10^{5}$ cells $/ \mathrm{mL}$. Twenty microliters of MTT reagent (R\&D Systems; Minneapolis, MN) was added per $100 \mu \mathrm{L}$ culture volume and the cells were incubated for $4 \mathrm{~h}$ at $37^{\circ} \mathrm{C}$. Finally, the absorbance at $570 \mathrm{~nm}$ $\left(\mathrm{A}_{570}\right)$ of each sample well was measured using an automated plate reader. The entire experiment (with all cell lines) was repeated at least twice.

\subsection{Data analysis}

Data in the text and figures are presented as means \pm SEM. All statistical analyses were carried out using SPSS 11.0 software (OriginLab). One-way ANOVA with Bonferroni correction was used for multiple group comparisons and the Wilcoxon $\mathrm{W}$ test was used for cell proliferation analysis. Differences were considered statistically significant when $\mathrm{p}<0.01$.

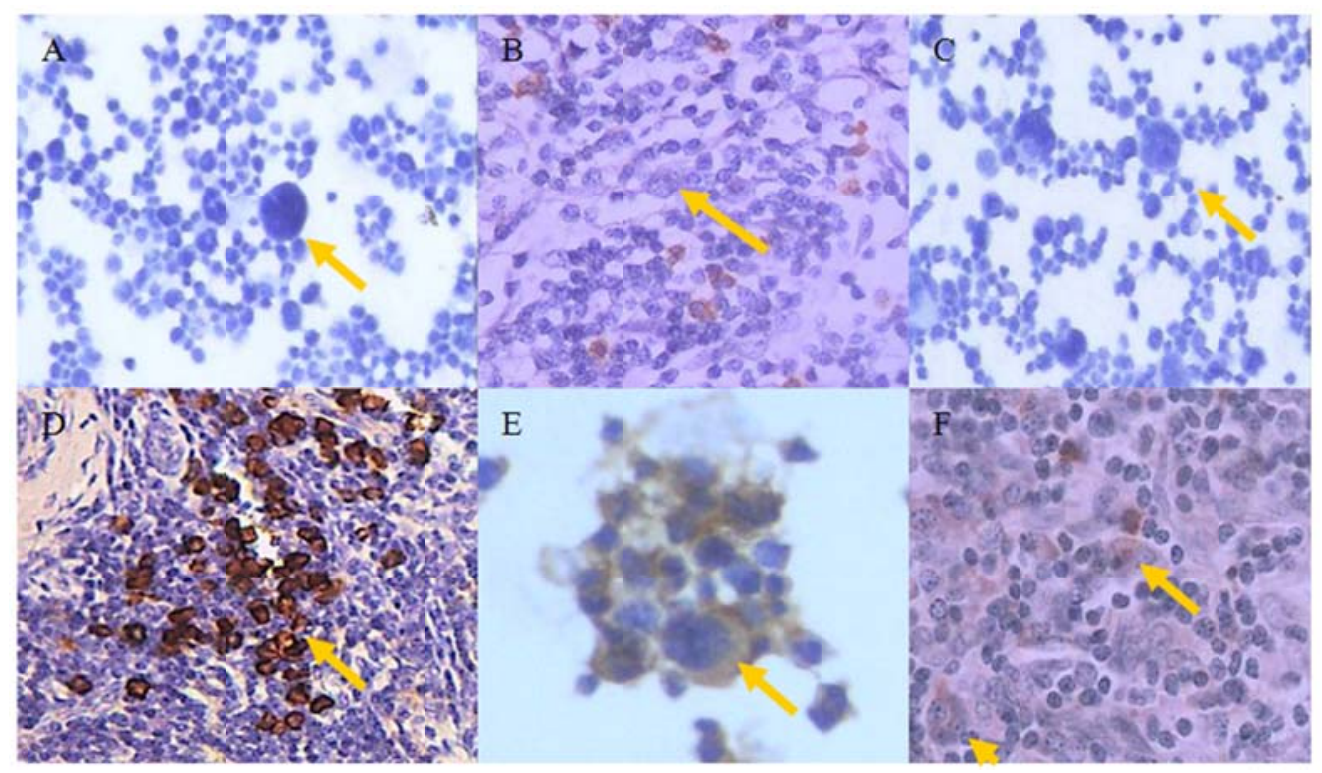

Figure 1. Evidence of a lack of CD99 expression in L428 cells (A); in biopsy samples (B); in L428-EVC (C); patients with HL are positive for NF- $\mathrm{kB}(\mathrm{F})$; staining for CD99 in lymphocytes served as positive control in the lymph nodes (D); in L428-MVC cells (E), arrows indicated. A, B, C, D, E, F 400×.

\section{Results}

\subsection{Immunohistochemical examination}

CD99 expression was negative in the L428 cell line (see Figure 1A) and the L428-EVC negative control cell line (see Figure 1C). Fourteen of fifteen patients failed to express CD99 (Figure 1B), while all HL patients were NF-kB-positive (see Figure 1F). The remaining patient was weakly positive for CD99 $(\mathrm{p}<0.01)$. Positive staining for CD99 was observed in lymphocytes in lymph nodes (see Figure 1D) and in L428-MVC cells (Figure 1E). Lymphocytes in the lymph nodes served as positive controls. 


\subsection{Direct sequencing}

The amplified CD99 and GAPDH genes were visualized by $2 \%$ agarose gel electrophoresis. CD99 expression (see Figure 2A L3) in the L428-MVC cell line and GAPDH expression (see Figure 2A L1, L2, L4) in the L428, L428-EVC, and L428-MVC cell lines were evident. In this gel, lane 5 is the negative control (see Figure 2A L5). The vector driving CD99 expression in the stable L428-MVC cell line was sequenced, and the presence of the CD99 sequence was confirmed (see Figure 2B).

Figure 2A. Results of RT-PCR electrophoresis. Mic2 (L3) in the L428-MVC cells and the GAPDH gene (L1, L2, L4) in the L428, L428-EVC, and L428-MVC cells are evident. L5 served as a negative control.

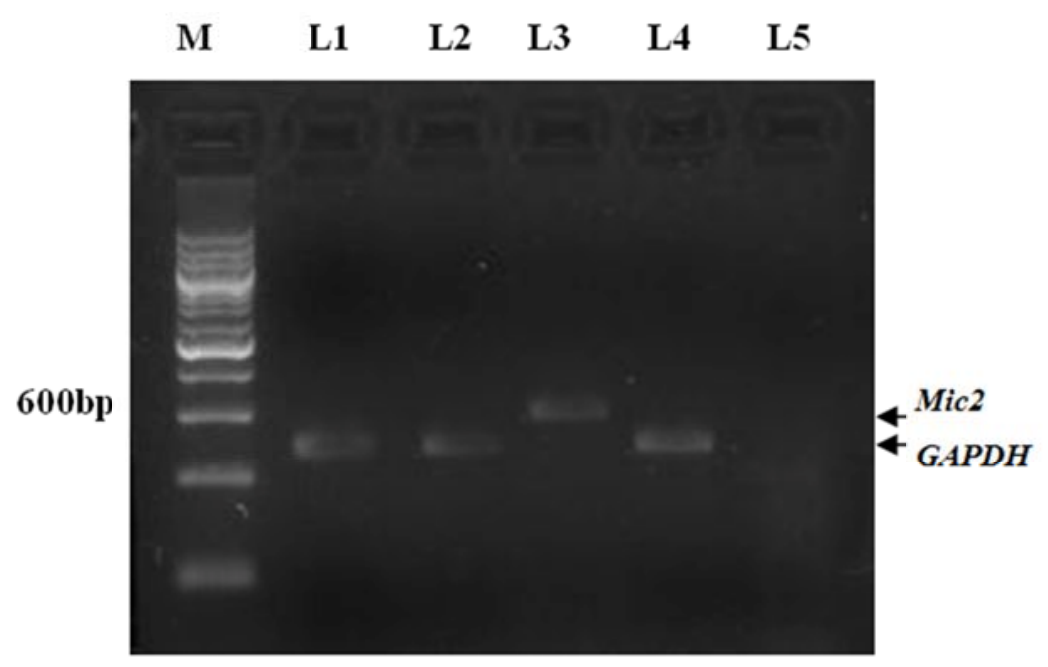

Abbreviation: $\mathrm{L}=$ Lane

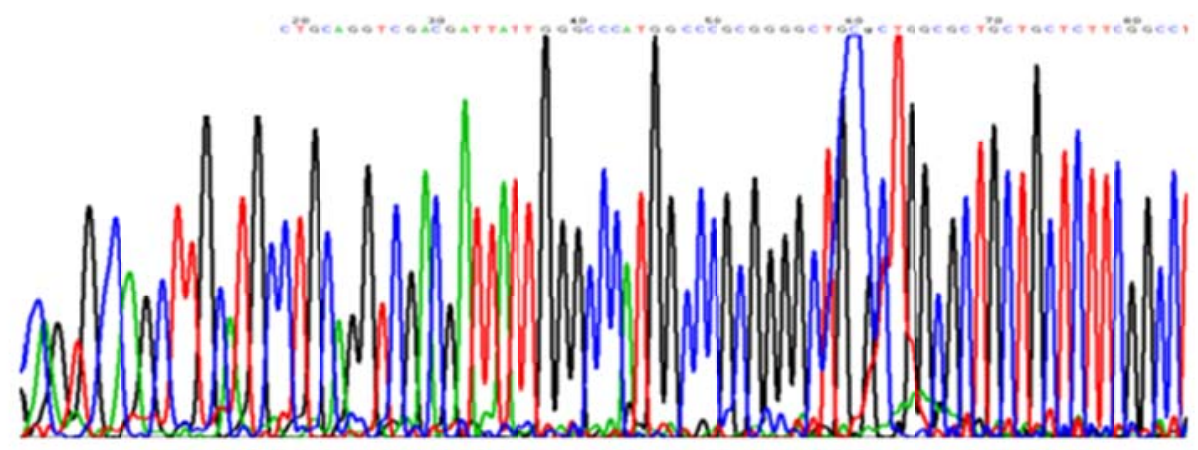

Figure 2B. Mic2 of L428-MVC cell line was sequenced. The result of CD99 sequence was confirmed.

\subsection{Protein expression}

We investigated changes in L428 cells caused by upregulation of CD99, particularly exploring the effects on immunophenotype. By IHC, we found that the L428 cells were positive for CD30 (see Figure 3A1) and CD15 (see Figure 3A2) and expressed NF-kBp65 (see Figure 4A); further, as expected, there was an absence of surface CD99 (see Figure 3A3). However, L428-MVC cells did not display CD30 (see Figure 3B1), CD15 (see Figure 3B2), CD2 (see Figure 3B4), CD3 (see Figure 3B5), CD20 (see Figure 3B6), or CD79 (see Figure 3B7) on their surface; further, they did not express NF-kBp65 (see Figure 4B) but did express CD99 (see Figure 3B3). In L429-EVC cells, there was restored expression of CD30 (see Figure 3C1), CD15 (see Figure 3C2) and NF-кBp65 (see Figure 4C), but no expression of CD2 (see Figure 3C4), CD3 (see Figure 3C5), CD20 (Fig.3C6), and CD79 (see Figure 3C7). 


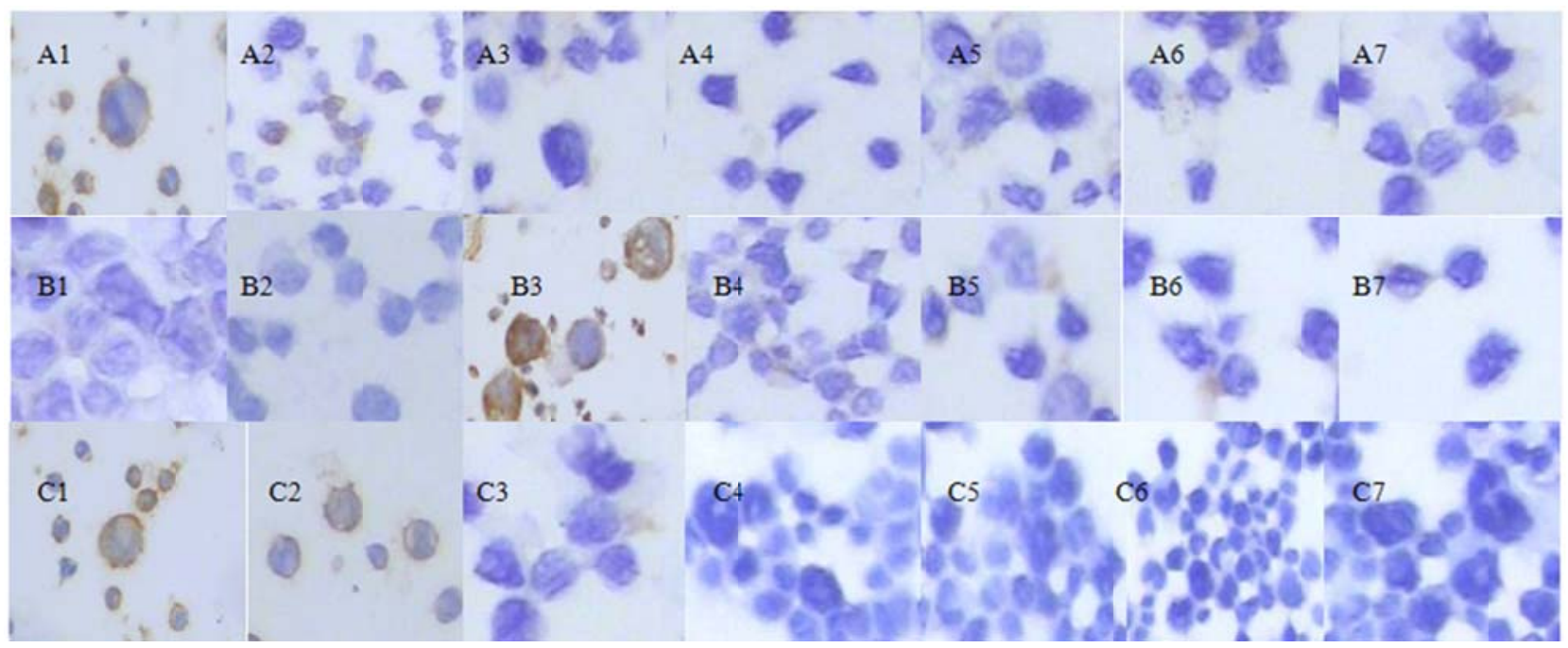

Figure 3. Negative for CD30(B1),CD15(B2),CD2(B4),CD3(B5),CD20(B6) and CD79(B7) while the positive for CD99 (B3) in L428-MVC cells during continuous passages. (L428,L428-EVC) are positive for CD30(A1,C1),CD15(A2,C2) compared with negative expression for CD99(A3,C3),CD2(A4,C4),CD3(A5,C5), CD20(A6,C6),CD79(A7,C7).Upper: L428; middle: L428-MVC; lower:L428-EVC $(\times 400)$.

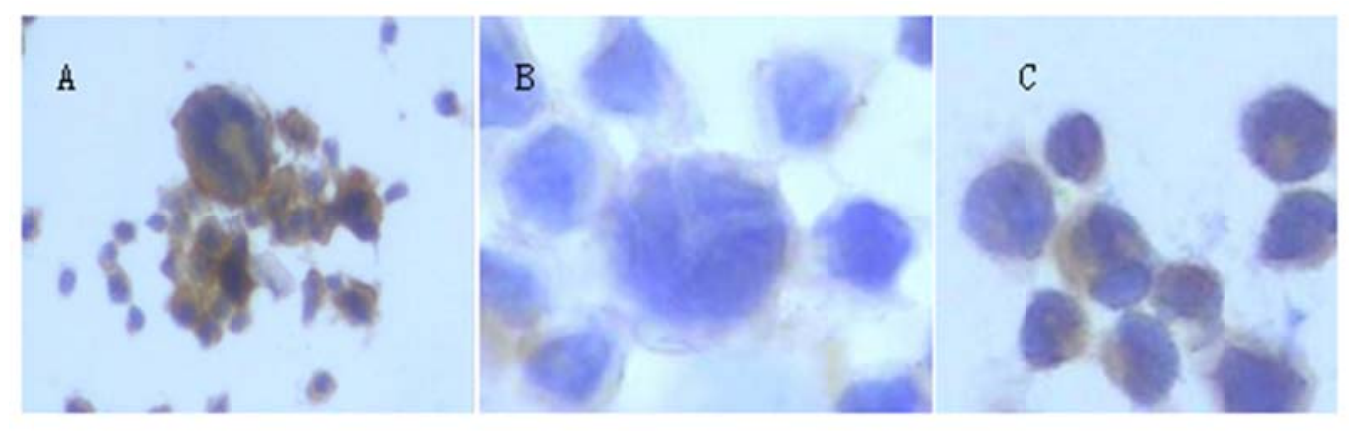

Figure 4. Positive staining for NF- $\mathrm{KB}$ in the L428 (A) cells while negative in L428-MVC (B) cells. There is no change in $\mathrm{L} 428-\mathrm{EVC}(\mathrm{C})(\times 400)$.

According to flow cytometry analysis, there was a significantly reduced percentage of cells expressing CD30 $(1.6 \% \pm 0.1 \%)$ and $\mathrm{CD} 15(0 \%)$ in the L428-MVC cell line compared to the percentage of cells expressing CD30 $(90.6 \% \pm 5.6 \%)$ and CD15 $(83.2 \% \pm 4.5 \%)$ in the L428 cell line $(\mathrm{p}<0.01)$. However, there was no significant difference in the percentage cells positive for $\mathrm{CD} 30(87.6 \% \pm 5.3 \%)$ and $\mathrm{CD} 15(80.5 \% \pm 4.1 \%)$ in the L428-EVC cell line. Interestingly, the expression of CD20 and CD79 expression was absent (0\%) in the L428-MVC cell line, indicating that the L428-MVC cell line could not be transformed B-cell lymphoma cells by an upregulation of CD99 expression. Silencing CD99 in the

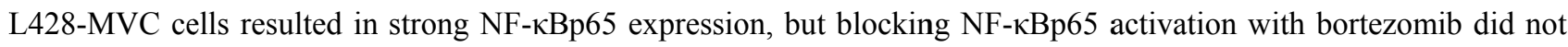
result in decreased CD99 expression, suggesting that CD99 downregulated NF- $\mathrm{kBp} 65$ expression.

\subsection{NF-KBp65 is inactivated by CD99}

In order to investigate whether CD99 altered the activation of NF- $\mathrm{kBp} 65$, we transfected a CD99 expression construct into L428 cells and found a significant reduction in NF- $\mathrm{kBp} 65$ activation in L428-MVC cells by immunofluorescence (see Figure 5C2) and Western blot analysis ( see Figure 6D, E, F). There was no CD99 expression when NF- $\mathrm{kBp} 65$ activation was blocked with bortezomib in the L428 (see Figure 6N) and L428-EVC (see Figure 6O) cell lines. After we inhibited the 
expression of CD99 with siRNA against CD99 in L428-MVC cells, expression of NF-kBp65 was evident (see Figure 6C). However, there was only a small change in the activation of NF- $\mathrm{BBp} 65$ in L428-EVC cells according to immunofluorescence (Figure 5B1, B2) and Western blot analysis (see Figure 6C, H). These findings demonstrate that the signaling pathways upstream of CD99 influence NF-кBp65 expression and activation in L428 cells.
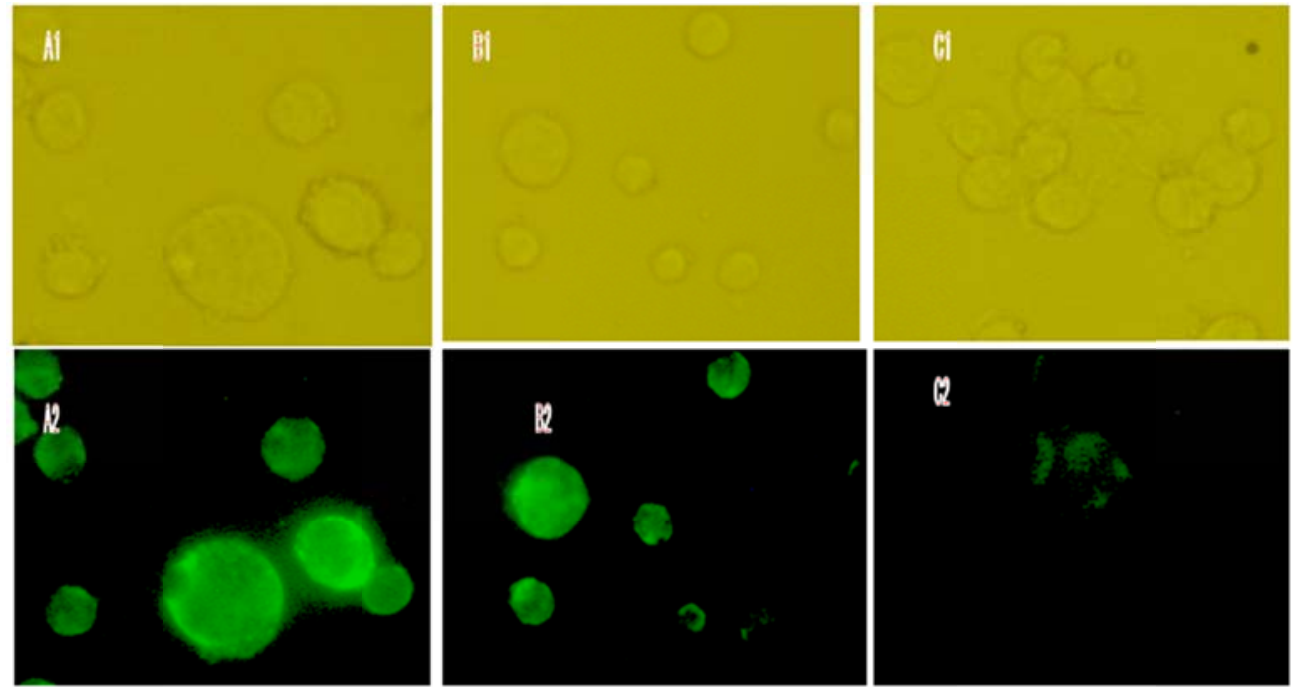

Figure 5. Significantly reduced the magnitude of NF- $\mathrm{kBp} 65$ activation in L428-MCV cells (C2). The activation of NF- $\kappa B p 65$ tiny change in L428-EVC cells (B2) and in L428 cells (A2). Upper: optical microscope; lower: Fluorescence microscope. A1, A2: L428 cells; B1, B2: L428-EVC cells; C1, C2: L428-MVC cells ( $\times 400)$.

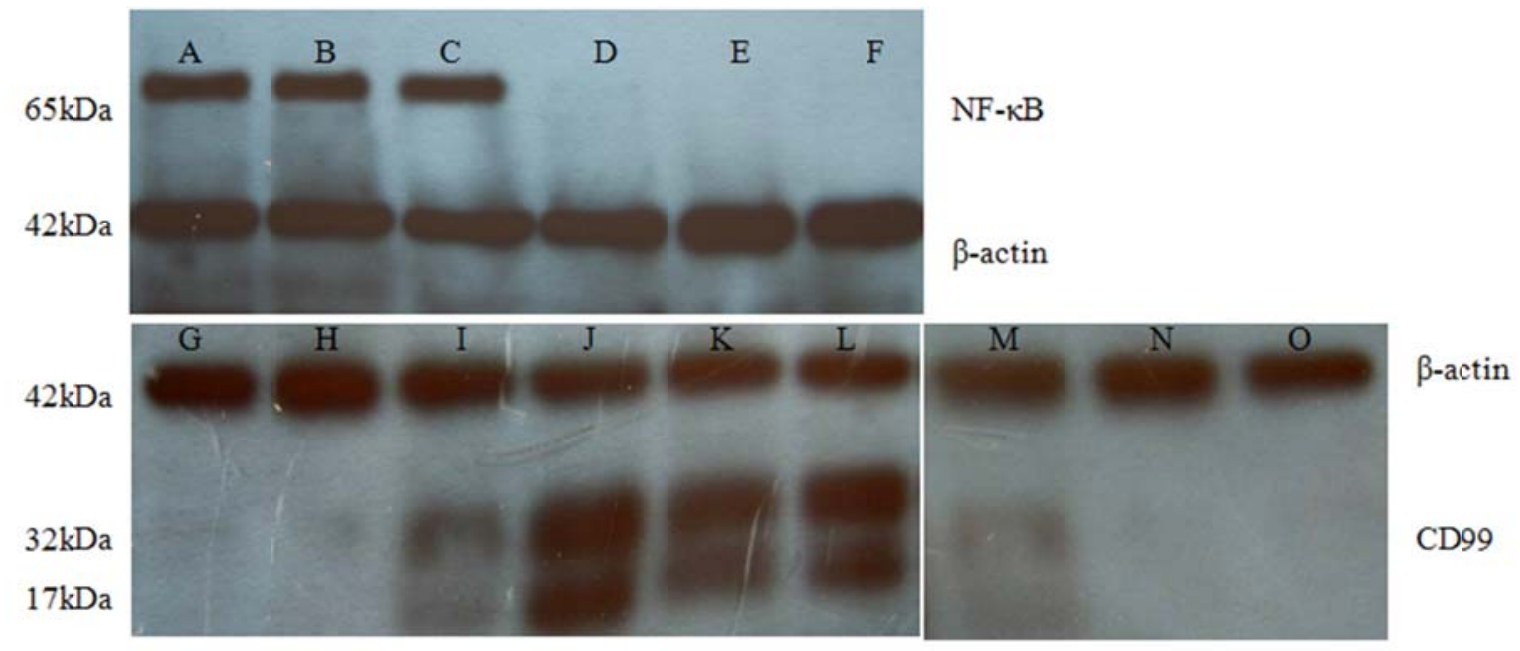

Figure 6. CD99 influenced NF- $\kappa$ Bp65 activation. (A), (B) and (G) in L428 cells, (C) and (H) in L428-EVC cells, (D), (E), (F), (I), (J), (K), (L) in L429-MVC. (N) and (O) blocked with Bortezomib in L428 and L428-EVC cells, (M) blocked with Bortezomib in L428-MVC.

\subsection{Flow cytometric analysis}

L428-MVC cell clones displayed an intermediate reduction in their proliferation rate, suggesting that CD99 could inhibit cell growth; this was confirmed with cell cycle analysis. Cells were stably transfected with CD99 to see whether this blocked cell cycle progression into the S-phase. G2/M arrest was then correlated with apoptosis. The percentage of cells 
arrested in G2/M was greater in the L428-MVC cell line, and the number of apoptotic L428-MVC cells exceeded that of the L428 and L428-EVC cell lines relative to the number of cells in G2/M arrest (see Figure 7) ( $<0.01$ ). In considering these results, it is important to recognize that the induction of cell cycle arrest and apoptosis was related to the introduction of CD99.

\subsection{Cell proliferation assays}

The cells were counted following trypan blue staining. Both L428 and L428-MVC cells were growing well within 7 days and continued to grow for 8-10 days. MTT assays also indicated that L428, L428-EVC, and L428-MVC cells proliferated. However, the proliferation of L428-MVC cells was significantly less than that of L428 and L428-EVC cells $(\mathrm{p}<0.01)$. Because there was no significant difference in proliferation between L428 cells and L428-EVC cells ( $>0.01$ ), we concluded that the proliferation of L428 cells was reduced by CD99 upregulation (see Figure 8). All experiments were performed three times.

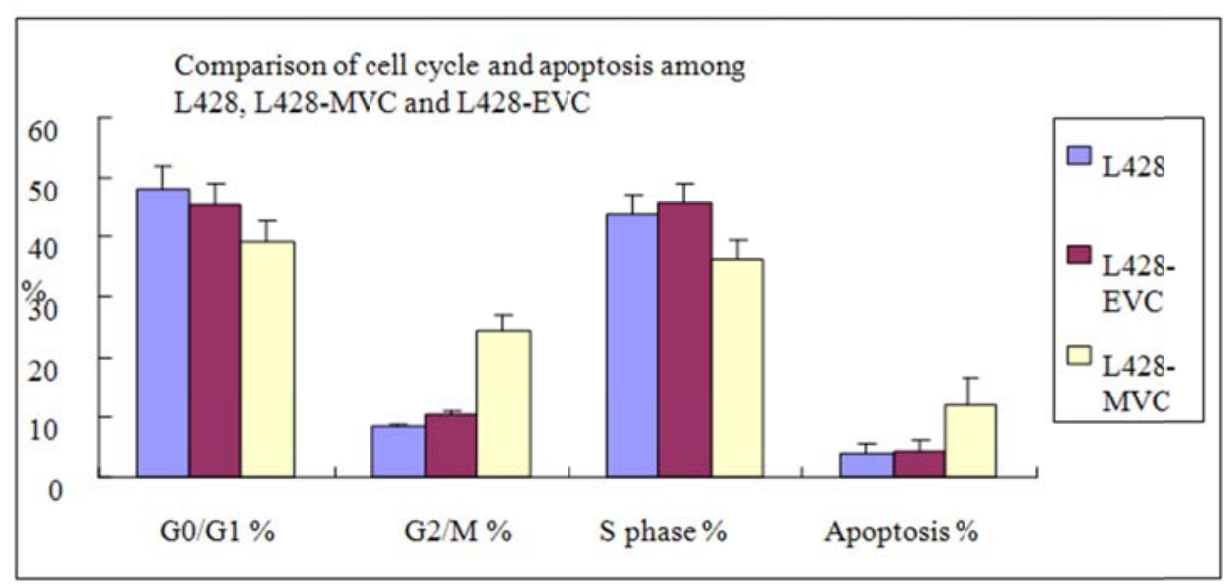

Figure 7. FACS analysis of progression into the S-phase of L428, L428-EVC and L428-MVC. Percentage of L428-MVC cells lines arrested in G2/M compared with L428 and L428-EVC cells. The apoptosis of L428-MVC cells lines exceeded that of L428 and L428-EVC cells relative to the number of cells in G2/M arrest $(\mathrm{p}<0.01)$.

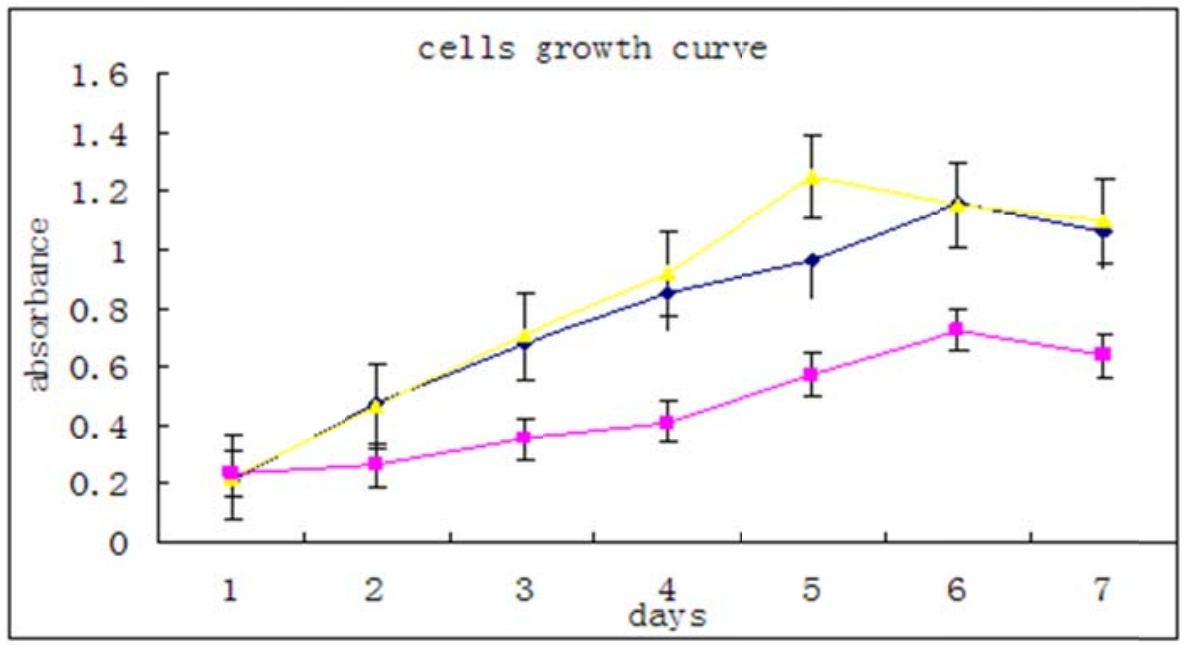

Figure 8. Proliferation rates of L428 (blue),L428-EVC(yellow) cells and L428-MVC(red).Cells absorbance at various days after seeding is indicated(L428,L428-EVC cells versus L428-MVC cells, p<0.01). A, B, C 400×. 


\section{Discussion}

$\mathrm{HL}$ is different from other tumors due to its special pathological feature: the malignant HRS cells. These generally account for only a very small part of the tumor tissue, in which the predominant cells are a large number of lymphocytes in the background. We determined the immunophenotype of the L428 cells employed in the experiment to explore the growth characteristics of HRS cells. Our results lay the foundation for addressing whether cells of different morphology can mutually convert and whether this is related to NF-kB activation.

In this study, we elucidated a critical function of CD99 in L428 cell lines. This is the first study demonstrating changes in the morphology and functional characteristics of the HL cell line L428 following upregulation of CD99. Immunohistochemical examination of sections from the lymph nodes sections of patients with different HL subtypes revealed that CD99 was undetectable in patients with HL on RS cells and L428 cell lines, while patients with HL are positive for NF- $\kappa B$; this is in agreement with a previous report ${ }^{[8]}$. Moreover, L428 cells were negative for CD99. These findings support the hypothesis that CD99 was not silenced but absent. Meanwhile, the results also indicated that inhibition of CD99 produced HRS cells in B lymphoma ${ }^{[8]}$. This raises the question of what role CD99 plays in HL cells lines. The approach of upregulating or silencing CD99 may help us to understand the molecular mechanisms of this protein in HL cells lines.

In this study, we uncovered a critical function of CD99 in L428 cells. We found that CD99 played a key role, altering the morphological and functional characteristics of HL cells. The expression of CD30 and CD15 are currently used as immunophenotypic criteria for the diagnosis of $\mathrm{HL}^{[13,14]}$ while $\mathrm{CD} 20$ is used as a surface marker of $\mathrm{B}$ cell lymphoma. Transfection of CD99 into L428 cells caused the disappearance of most of the features of HRS cells, including the expression of CD30 and CD15, and cell size became smaller as well. L428-MVC cells did not transform to B-cell lymphoma because expression of CD20 and CD79 was negative.

Interestingly, we also transfected L428 cells with an empty vector construct as a negative control, as well as with siRNA against CD99, and found that neither the morphology nor the functional characteristics changed. Thus, it appears that the presence of CD99 accounted for the changes in L428 cell morphology. The role of CD99 in the generation of HRS-like cells has been reported previously ${ }^{[8]}$. This is of particular interest, as CD99 has been suggested to be a key factor to be involved in the pathogenesis of Hodgkin lymphoma and EBV-associated lymphomatosis disease. The results presented here confirmed the role of CD99 in L428 cells in a reverse manner (by forced CD99 upregulation rather than downregulation) and are important in further characterizing the role of CD99 in HL.

To evaluate the proliferation of the L428, L428-EVC, and L428-MVC cell lines, we investigated their growth characteristics. L428-MVC cells showed markedly decreased proliferation rates as compared to the L428 and L428-EVC cell lines. Moreover, L428-MVC cells had higher percentage of G2/M phase cells as compared to the L428 and L428-EVC cell lines according to flow cytometric analysis. These results are in agreement with a previous report that the majority of HRS cells appear to be in the G2/M phase of the cell cycle ${ }^{[6]}$. We conclude that CD99 increases the number of cells in G2/M phase and also has an apoptotic effect, which result in mildly attenuated rates of cell growth. This may occur via the $\mathrm{NF}-\kappa \mathrm{B}$ signal transduction pathways.

Some recent studies provide support for the proposal that CD99 may be crucial for cancer development and also plays a pivotal role in the reversion of malignant phenotypes ${ }^{[15]}$, although this hypothesis requires further study. A number of studies have demonstrated that CD99 and CD3 co-stimulation leads to a concomitant enhancement of NF- $\mathrm{BB}$ signaling activity ${ }^{[16,17]}$, but our results indicate that NF- $\mathrm{KB}$ was not expressed in L428-MVC. Furthermore, we found no expression of NF- $\mathrm{KB}$ when CD99 was transfected into the L428 cell line. NF- $\mathrm{KB}$ activation can maintain tumor cell viability, and an inhibition of NF- $\kappa B$ activity alone can be sufficient to induce cell death ${ }^{[18]}$. Recent evidence also suggests that activated $\mathrm{NF}-\kappa \mathrm{B}$ protects HL cells, allowing them to evade apoptosis ${ }^{[19]}$. 
We found that the NF-kB signaling pathway was activated in L428 cells. A previous report showed that CD30 mediates $\mathrm{NF}-\kappa \mathrm{B}$ activation in $\mathrm{HL}^{[20]}$. It was therefore speculated that the NF- $\mathrm{\kappa B}$ signaling pathway may participate in the

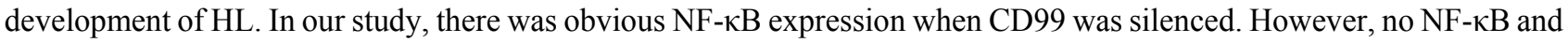
no CD99 expression were noted when activation of NF-kBp65 was inhibited with bortezomib. These results suggest that the effects of CD99 on the morphology and functional characteristics of L428 cells occur through downregulation of the NF- $\kappa B$ signaling pathway. Activation of NF- $\mathrm{kBp} 65$ may be a viable target for the treatment of Hodgkin's lymphoma. In fact, the siRNA and in vivo studies indicate that CD30 and CD15 downregulation is mediated by forced CD99 expression, and this downregulation may in turn inactivate NF- $\mathrm{KB}$ signaling.

The Blood series studies already suggested that the downregulation of CD99 was closely related to the activation of $\mathrm{NF}-\mathrm{\kappa B}$, although the EBV protein LMP-1 is another key component in this relationship ${ }^{[19,20]}$. Because L428 is an EBV(-) cell line, our study investigates the role of CD99 associated with NF-kB in an EBV(-) HL model, and CD99 seems to interrupt the activation of NF- $\mathrm{kB}$ is an independent event from LMP-1, as EBV is one of the most important causes of HL development.

Our results suggest that CD99 may play a major role in inducing the morphological and functional changes seen in L428 cells through the downregulation of the NF-kBp65 signaling pathway.

\section{Acknowledgments}

We thank Michael D Kurtz for editing the manuscript. We thank Xin Wang for helping with the manuscript preparation, Gong Zhang for photography work, and Xiao Yuang Chen for support and helpful comments. We also thank all members of the Laboratory of Molecular Tumor Pathology for their helpful suggestions.

\section{References}

[1] Felberbaum RS. The molecular mechanisms of classic Hodgkin's lymphoma. Yale J Biol Med. 2005; 78(4):203-10. PMid:16720015

[2] Jarrett RF. Viruses and Hodgkin lymphoma. Ann Oncol. 2002; 13 Suppl 1:23-29. PMid:12078898 http://dx.doi.org/10.1093/annonc/13.S1.23

[3] Hinz M, Lemke P, Anagnostopoulos I, et al. Nuclear factor kappaB-dependent gene expression profiling of Hodgkin lymphoma tumor cells, pathogenetic significance, and link to constitutive signal transducer and activator of transcription 5a activity. J Exp Med. 2002; 196: 605-17. PMid:12208876 http://dx.doi.org/10.1084/jem.20020062

[4] Lee EK, Chae JH, Kang MS. et al. Nuclear factor- $\kappa B 2$ represses Sp1-mediated transcription at the CD99 promoter.Mol Cells. 2011 Dec; 32(6):555-60. PMid:22083306 http://dx.doi.org/10.1007/s10059-011-0177-5

[5] Maggio E, van den Berg A, de Jong D, et al. Low frequency of FAS mutations in Reed Sternberg cells of Hodgkin lymphoma. Am J Pathol. 2003; 162:29-35. http://dx.doi.org/10.1016/S0002-9440(10)63795-9

[6] Tzankov A, Zimpfer A, Went P, et al. Aberrant expression of cell cycle regulators in Hodgkin and Reed-Sternberg cells of classical Hodgkin's lymphoma. Mod Pathol. 2005; 18(1):90-6. PMid:15389259 http://dx.doi.org/10.1038/modpathol.3800276

[7] Chan WC. The Reed-Sternberg cell in classical Hodgkin's disease. Hematol Oncol. 2001; 19(1):1-17. PMid:11276042 http://dx.doi.org/10.1002/hon.659

[8] Kim SH, Choi EY, Shin YK, et al. Generation of cells with Hodgkin's and Reed-Sternberg phenotype through downregulation of CD99 (CD99). Blood. 1998; 92(11):4287-95. PMid:9834235

[9] Lou O, Alcaide P, Luscinskas FW, Muller WA.CD99 is a key mediator of the transendothelial migration of neutrophils. J Immunol. 2007; 178(2):1136-43. PMid:17202377

[10] Imbert AM, Belaaloui G, Bardin F, et al. CD99 expressed on human mobilized peripheral blood CD34+ cells is involved in transendothelial migration. Blood. 2006; 108(8): 2578-86. PMid:16825498 http://dx.doi.org/10.1182/blood-2005-12-010827

[11] Olsen SH, Thomas DG, Lucas DR. Cluster analysis of immunohistochemical profiles in synovial sarcoma, malignant peripheral nerve sheath tumor, and Ewing sarcoma. Mod Pathol. 2006; 19(5):659-68. PMid:16528378

http://dx.doi.org/10.1038/modpathol.3800569 
[12] Sung CO, Ko YH, Park S, et al. Immunoreactivity of CD99 in non-Hodgkin's lymphoma: unexpected frequent expression in ALK-positive anaplastic large cell lymphoma. J Korean Med Sci. 2005; 20(6):952-56. PMid:16361803 http://dx.doi.org/10.3346/jkms.2005.20.6.952

[13] Anagnostopoulos I, Hansmann ML, Franssila K, et al. European Task Force on Lymphoma project on lymphocyte predominance Hodgkin disease: histologic and immunohistologic analysis of submitted cases reveals 2 types of Hodgkin disease with a nodular growth pattern and abundant lymphocytes. Blood. 2000; 96:1889-99. PMid:10961891

[14] Nogová L, Rudiger T, Engert A. Biology, clinical course and management of nodular lymphocyte-predominant Hodgkin lymphoma. Hematology. 2006; 1: 266-72. PMid:17124071

http://dx.doi.org/10.1182/asheducation-2006.1.266

[15] Scotlandi K, Zuntini M, Manara MC, et al. CD99 isoforms dictate opposite functions in tumour malignancy and metastases by activating or repressing c-Src kinase activity. Oncogene. 2007; 26(46):6604-18. PMid:17471235 http://dx.doi.org/10.1038/sj.onc.1210481

[16] Yoon SS, Kim HJ, Chung DH, et al.CD99 costimulation up-regulates T cell receptor-mediated activation of JNK and AP-1.1: Mol Cells. 2004; 18(2):186-91. PMid:15528994

[17] Oh KI, Kim BK, Ban YL, et al.CD99 activates T cells via a costimulatory function that promotes raft association of TCR complex and tyrosine phosphorylation of TCR zeta. Exp Mol Med. 2007; 39(2):176-84. http://dx.doi.org/10.1038/emm.2007.20

[18] Darnell, JE Jr. Transcription factors as targets for cancer therapy. Natl. Rev. Cancer 2002; 2:740. PMid:12360277 http://dx.doi.org/10.1038/nrc906

[19] Dutton A, Woodman CB, Chukwuma MB, et al. Bmi-1 is induced by the Epstein-Barr virus oncogene LMP1 and regulates the expression of viral target genes in Hodgkin lymphoma cells. Blood, 2007; 109(6):2597-603. PMid:17148591 http://dx.doi.org/10.1182/blood-2006-05-020545

[20] Böll B, Hansen H, Heuck F, et al. The fully human anti-CD30 antibody 5F11 activates NF- $\kappa$ B and sensitizes lymphoma cells to bortezomib-induced apoptosis. Blood. 2005; 106(5):1839-42. PMid:15878978 http://dx.doi.org/10.1182/blood-2005-01-0427

[21] Kawakami M, Kawakami K, Kioi M, et al. Hodgkin lymphoma therapy with interleukin-4 receptor-directed cytotoxin in an infiltrating animal model. Blood. 2005; 105(9):3707-13. PMid:15626735 http://dx.doi.org/10.1182/blood-2004-08-3216

[22] Dewan MZ, Watanabe M, Ahmed S, et al. Hodgkin's lymphoma cells are efficiently engrafted and tumor marker CD30 is expressed with constitutive nuclear factor-kappaB activity in unconditioned NOD/SCID/gammac(null) mice. Cancer Sci. 2005; 96(8):466-73. PMid:16108827 http://dx.doi.org/10.1111/j.1349-7006.2005.00079.x 